\title{
First Evaluation of $P$ Dispersion and Tp-e Parameters in Electrocardiograms of Children with Diabetic Ketoacidosis
}

\author{
(D) Oğuz Eğil1, (D) Fatih Şap², (D) Beray Selver Eklioğlu33, (D) Mehmet Burhan Oflaz², (D) Mehmet Emre Atabek³, (D) Tamer Baysal2 \\ ${ }^{1}$ Necmettin Erbakan University, Meram Faculty of Medicine, Department of Pediatrics, Konya, Turkey \\ ${ }^{2}$ Necmettin Erbakan University, Meram Faculty of Medicine, Department of Pediatrics, Division of Pediatric Cardiology, Konya, Turkey \\ ${ }^{3}$ Necmettin Erbakan University, Meram Faculty of Medicine, Department of Pediatrics, Division of Pediatric Endocrinology, Konya, Turkey
}

\begin{abstract}
What is already known on this topic?
Diabetic ketoacidosis (DKA) is one of the leading causes of morbidity and mortality in children with type 1 diabetes mellitus. Atrial and ventricular arrhythmias are commonly seen during DKA. On electrocardiography (ECG), P-wave dispersion (Pd) has been associated with risk of atrial arrhythmias. QT dispersion (QTd), corrected QTd (QTcd), Tp-e duration, Tp-e/QT and Tp-e/QTc indicate the risk of ventricular arrhythmias.
\end{abstract}

What this study adds?

To the best of our knowledge, this is the first article evaluating Pd, Tp-e, Tp-e/QT and Tp-e/QTc parameters in children with DKA. In this study, cardiac arrhythmia risk markers, including Pd, QTd, QTcd and Tp-e, Tp-e/QT, were found to be increased in children with DKA.

\begin{abstract}
Objective: Diabetic ketoacidosis (DKA) is an important complication of type 1 diabetes mellitus. We aimed to evaluate the effect of metabolic disorders of DKA on electrocardiography (ECG) parameters in children.

Methods: This study was performed between December 2018 and March 2020 and included 39 children with DKA and 40 healthy children. Three ECGs (one before and two after treatment) were obtained from the patient group. P-wave dispersion (Pd), QT dispersion (QTd), QTc dispersion (QTcd), Tp-e intervals, and the ratios of Tp-e/QT and Tp-e/QTc were measured electrocardiographically. ECG parameters from children with DKA and healthy controls were compared statistically.

Results: The mean age of the patient group was $10.50 \pm 4.12$ years. There was no significant difference in terms of age, gender, weight, height and body mass index between patients and controls. In the patient group, a statistically significant increase was found in Pd, QTd and QTcd in the initial ECG compared to the second and third ECGs. Also, when the first and third ECGs were compared, a significant increase in Tp-e and Tp-e/QT was evident in the first ECG. There was a significant difference in the values of Pd, QTd, QTcd, Tp-e and Tp-e/QT in the first ECGs, obtained before DKA treatment, and those values obtained from the control group.

Conclusion: This is the first article evaluating Pd and Tp-e parameters in children with DKA. Cardiac arrhythmia risk markers were increased in children with DKA compared to controls. Therefore, clinicians should be aware of the possibility of developing new arrhythmias during DKA treatment.
\end{abstract}

Keywords: Cardiac arrhythmia, children, diabetic ketoacidosis, electrocardiography

\section{Introduction}

Type 1 diabetes mellitus (T1DM) accounts for about $10 \%$ of all diabetic cases, and more than 3 million people in the United States and 15 million people worldwide are affected (1). Diabetic ketoacidosis (DKA) is one of the leading causes of morbidity and mortality in children with T1DM (2). In diabetic individuals, morbidity and mortality of cardiovascular diseases were found to be increased when compared to healthy individuals. The incidence of diseases such as myocardial infarction and ischemic stroke has also increased (3).
Address for Correspondence: Oğuz Eğil MD, Necmettin Erbakan University, Meram Faculty of Medicine, Department of Pediatrics, Konya, Turkey

E-mail: oguzegil@hotmail.com ORCID: orcid.org/0000-0001-5112-5733

${ }^{\circ}$ Copyright 2022 by Turkish Pediatric Endocrinology and Diabetes Society

The Journal of Clinical Research in Pediatric Endocrinology published by Galenos Publishing House.
Conflict of interest: None declared Received: 14.01 .2021 Accepted: 18.08.2021 
Malignant cardiac arrhythmias resulting in sudden cardiac death may be present in individuals who are presumably healthy or with medical problems (4). There are some electrocardiographical (ECG) markers that may be associated with cardiac arrhythmias $(4,5)$. On ECG, P-wave dispersion $(\mathrm{Pd})$ has been associated with a risk of atrial arrhythmias. Increased $\mathrm{Pd}$ represents non-homogeneous propagation of sinus impulses and atrial depolarization abnormalities associated with atrial arrhythmia (5). QT dispersion (QTd), corrected QT (QTc), and corrected QTd (QTcd) indicate heterogeneity of ventricular repolarization. An increase in ventricular heterogeneity increases myocardial electrical sensitivity and predisposes to ventricular arrhythmias. Tp-e duration, the interval between the peak and the end of the $\mathrm{T}$ wave, is also a useful parameter for predicting cardiac arrhythmias and Tp-e/QT and Tp-e/QTc are considered more beneficial than QTd (4).

In the light of recent evidence, we aimed to evaluate atrial (Pd) and ventricular arrhythmia risk markers (QTd, QTcd, Tp-e, Tp-e/QT and Tp-e/QTc) on ECG during and after DKA in children with T1DM.

\section{Methods}

\section{Selection of Study Populations}

This study was conducted prospectively inchildren diagnosed with DKA between December 2018 and March 2020 in a tertiary child health care center. In the patient group, cases with pre-existing heart disease or dysrhythmia, or syndromes and sequences associated with cardiac components, or chronic disease other than diabetes mellitus (DM) were excluded from the study. Exclusion criteria for the control group were the presence of known heart disease or dysrhythmia, syndromes and sequences associated with cardiac components, and other chronic diseases.

The diagnostic criteria for DKA were hyperglycemia (blood glucose > $200 \mathrm{mg} / \mathrm{dL}$ ), ketosis (ketone positivity in blood or urine) and metabolic acidosis ( $\mathrm{pH}<7.3$ in venous blood sample or plasma bicarbonate $<15 \mathrm{mEq} / \mathrm{L}$ ), in accordance with literature (2).

In the patient group, a history of being previously or newly diagnosed with T1DM, age at diagnosis and follow-up duration, age at the occurrence of DKA, gender, weight, height and body mass index (BMI), blood pressure and biochemical values, including blood glucose levels at the time of DKA, hemoglobin A1C (HbA1c) and lipid panel taken in the last three months were examined. The clinical severity of DKA in patients was classified into: mild ( $\mathrm{pH}$ : 7.2-7.3, bicarbonate: $10-15 \mathrm{mEq} / \mathrm{L})$; moderate $(\mathrm{pH}$ : 7.1 -
7.2, bicarbonate: $5-9 \mathrm{mEq} / \mathrm{L})$; and severe $(\mathrm{pH}:<7.1$, bicarbonate: $<5 \mathrm{mEq} / \mathrm{L}$ ) (6). No blood tests were performed in the control group.

\section{Electrocardiography}

ECG examination was performed in all cases. Recordings were obtained with a speed of $25 \mathrm{~mm} / \mathrm{s}$ and amplitude of 10 $\mathrm{mm} / \mathrm{mV}$ using SeaMed ECG 1200G (Qinhuangdao, China) 12-channel/12-lead ECG device. All ECGs were scanned at a resolution of 300 DPI and transferred to electronic medium. Images were analyzed with "Adobe Photoshop CS2 version 9.0" program at a resolution of 1500 DPI and accuracy of four milliseconds. A total of three ECG recordings were obtained from the patient group; the first at the time of DKA, the second shortly after recovery from the DKA (3-7 days later), and the third approximately 1-2 weeks later after discharge from hospital. Only one ECG record was performed in each subject in the control group. Standard measurements, such as heart rate (HR), PR interval, P-wave duration, QT interval and QTc interval were performed on all ECGs, and then Pd, QTd, QTcd, Tp-e, and the ratios of Tp-e/QT and Tp-e/QTC were measured electrocardiographically. P-wave duration was evaluated as the duration between initial deflection and its return junction to the isoelectric baseline. QT interval was calculated as the duration between the beginning of the QRS complex and the end of T-wave in isoelectric baseline. QTc was measured using Bazett's formula $(\mathrm{QTC}=\mathrm{QT} / \sqrt{\mathrm{RR}})$. Tp-e interval was evaluated as the duration between the peak and the end of the $\mathrm{T}$ wave on isoelectric baseline. If the beginning and end of the $\mathrm{T}$ waves were not clearly seen, it was determined according to the tangent method defined by Lepeschkin and Surawicz (7). In this study, Pd, QTd and QTcd were measured from at least nine leads, and the Tp-e interval was evaluated primarily using V5, and if not possible, then preferentially by V4 or V6 derivation. Measurements were made in three consecutive heartbeats and the average was calculated. The $U$ wave, if present, was not included in the Tp-e range. While calculating Tp-e/QT and Tp-e/QTc ratios, QT and QTc were measured from the same derivation where Tp-e interval was measured.

\section{Echocardiography}

Echocardiographic (ECHO) examination of the patient and control groups were also compared during this study. Evaluations were performed by an experienced pediatric cardiologist using a Vivid S5 N (General Electric, Horten, Norway) ECHO device and $3 \mathrm{~S}(2-4 \mathrm{MHz})$ probe. ECHO studies were performed using standard imaging techniques recommended by the American Society of Echocardiography (8). Left atrial diameter, aortic root, left ventricular endsystolic dimension, left ventricular end-diastolic dimension, 
end-diastolic interventricular septal thickness, end-diastolic left ventricular posterior wall thickness, left ventricular ejection fraction (EF) and left ventricular fractional shortening were measured echocardiographically.

All procedures performed in the current study were in accordance with the 1964 Helsinki Declaration and ethical approval for the study was obtained from Necmettin Erbakan University Ethical Committee with a decision no. 2018/1321, dated 03.05.2018.

Informed consent was obtained from all individual participants and/or their legal guardians included in the study.

\section{Statistical Analysis}

Statistical analysis was performed using Statistical Package for the Social Sciences statistics, version 22 (IBM Inc., Armonk, NY, USA). Continuous variables are expressed as mean \pm standard deviation when normal distribution is observed. Descriptive analysis was used in the analysis of the distribution and frequency of data. Chi-square test was used to evaluate categorical data in independent groups. The Kolmogorov-Smirnov and Shapiro-Wilk tests were used to determine whether the continuous variables fit the normal distribution or not. When homogeneous distribution was observed, an independent sample t-test (Student's t-test) was applied in independent groups and a dependent samples t-test (paired t) and two-way ANOVA tests were applied in dependent groups. In cases where normal distribution was not observed, Mann-Whitney U tests in independent groups, and Wilcoxon and Friedman tests in dependent groups were used. For correlation analysis, Pearson's correlation analysis was performed when the continuous variables were parametrically distributed and, if not, Spearman correlation analysis was used. During correlation examinations, the r-value was rated as: negligible between 0.00-0.29; weak between 0.30-0.49; moderate between 0.50-0.69; strong between 0.70-0.89; and very strong between 0.90-1.0 (9). A $\mathrm{p}<0.05$ was considered statistically significant.

\section{Results}

\section{Patient Demographic and Clinical Characteristics}

Forty children, aged 0-18 years with DKA as patient group and 40 age- and gender-matched healthy children as control group were included. However, one case from the patient group was excluded due to incomplete data. In the patient group $59.0 \%(n=23)$ were female $(F)$ and $41.0 \%(n=16)$ were male $(\mathrm{M})$ in patient group with a female to male $(\mathrm{F} / \mathrm{M})$ ratio of $1.44: 1$ in all patients with DKA $(n=39)$. While the F/M ratio was $3.25: 1$ in previously diagnosed T1DM patients, it was 0.83:1 in newly diagnosed patients. Mean ages of the patient and control groups were $10.50 \pm 4.12$ and $10.47 \pm 4.11$ years, respectively. There was no statistically significant difference between the patient and control groups in terms of gender, age, weight, height and BMI. General characteristics of the patients and controls are presented in Table 1.

The patient groups consisted of $43.6 \%(n=17)$ previously diagnosed patients and $56.4 \%(n=22)$ newly diagnosed patients. The mean duration of DM in previously diagnosed patients was $5.18 \pm 3.32$ years (range: $1-12$ years). Of the patients, $33.3 \%(n=13)$ presented with mild, $20.5 \%(n=8)$ moderate and $46.2 \%(n=18)$ severe DKA. Between these severity groups, there was no significant difference in terms of gender, history of being previously or newly diagnosed for T1DM and mean duration of diabetes ( $p>0.05$ for all).

There was a statistically significant decrease in both systolic and diastolic blood pressure in the patient group compared to the control group ( $p=0.006$ and $p=0.04$, respectively) (Table 1). As expected, leukocyte count and blood glucose values obtained at the time of DKA were above and sodium, $\mathrm{pH}$ and bicarbonate were below the laboratory reference ranges. Other data were within normal range according to laboratory references. In previously diagnosed cases the mean sodium level was $132.47 \pm 4.00 \mathrm{mmol} / \mathrm{L}$, mean potassium level was $4.54 \pm 0.96 \mathrm{mmol} / \mathrm{L}$, mean calcium level was $9.37 \pm 0.93 \mathrm{mg} / \mathrm{dL}$, mean phosphorus level was $4.21 \pm 1.37 \mathrm{mg} / \mathrm{dL}$, and mean magnesium level was $1.95 \pm 0.22 \mathrm{mg} / \mathrm{dL}$. Similarly, in newly diagnosed cases

Table 1. General characteristics of the cases

\begin{tabular}{llll}
\hline & Patient group $(\mathrm{n}=39)$ & Control group $(\mathrm{n}=40)$ & $\mathrm{p}$ \\
\hline Gender (female/male) & $23 / 16$ & $24 / 16$ & 0.926 \\
Age (year) & $10.50 \pm 4.12$ & $10.47 \pm 4.11$ & 0.948 \\
Weight $(\mathrm{kg})$ & $34.86 \pm 14.92$ & $38.51 \pm 18.49$ & 0.341 \\
Height $(\mathrm{cm})$ & $138.54 \pm 23.53$ & $143.19 \pm 24.16$ & 0.398 \\
Body mass index $\left(\mathrm{kg} / \mathrm{m}^{2}\right)$ & $17.34 \pm 4.60$ & $17.88 \pm 3.74$ & 0.301 \\
Systolic blood pressure $(\mathrm{mm} / \mathrm{Hg})$ & $101.89 \pm 13.69$ & $108.79 \pm 10.83$ & 0.006 \\
Diastolic blood pressure $(\mathrm{mm} / \mathrm{Hg})$ & $63.46 \pm 6.60$ & $68.18 \pm 9.51$ & 0.040 \\
\hline
\end{tabular}


the mean sodium level was $134.86 \pm 4.86 \mathrm{mmol} / \mathrm{L}$, mean potassium level was $4.36 \pm 0.72 \mathrm{mmol} / \mathrm{L}$, mean calcium level was $9.30 \pm 0.69 \mathrm{mg} / \mathrm{dL}$, mean phosphorus level was $3.79 \pm 1.33 \mathrm{mg} / \mathrm{dL}$ and mean magnesium level was $2.01 \pm 0.40 \mathrm{mg} / \mathrm{dL}$. In the patient group some laboratory abnormalities were seen, such as hyponatremia $(<136$ $\mathrm{mmol} / \mathrm{L})$ in $61.54 \% \quad(\mathrm{n}=24)$, hypernatremia $(>145$ $\mathrm{mmol} / \mathrm{L})$ in $2.56 \%(\mathrm{n}=1)$, hypokalemia $(<3.5 \mathrm{mmol} / \mathrm{L})$ in $15.38 \%(\mathrm{n}=6)$, hyperkalemia $(>5.1 \mathrm{mmol} / \mathrm{L})$ in $15.38 \%$ $(\mathrm{n}=6)$, hypophosphatemia $(<2.9 \mathrm{mg} / \mathrm{dL})$ in $17.95 \%$ $(\mathrm{n}=7)$, hyperphosphatemia ( $>5.1 \mathrm{mg} / \mathrm{dL})$ in $17.95 \%$ $(\mathrm{n}=7)$, hypocalcemia $(<8.4 \mathrm{mg} / \mathrm{dL})$ in $10.26 \%(\mathrm{n}=4)$, and hypercalcemia ( $>10.2 \mathrm{mg} / \mathrm{dL})$ in $15.38 \%(n=6)$. There was no statistically significant difference between the previously and newly diagnosed T1DM patients in terms of mean electrolyte levels of the patient group ( $p>0.05$ for all). The mean lipid values of the patient group were in the normal range, except for mild mean triglyceride elevation of $216.27 \pm 183.43 \mathrm{mg} / \mathrm{dL}(0-150 \mathrm{mg} / \mathrm{dL})$. The mean $\mathrm{HbA} 1 \mathrm{c}$ values were markedly above the reference range at $12.65 \pm 2.92 \%$ (normal range $4-6 \%$ ). There was no significant difference between the previously and newly diagnosed T1DM cases in terms of mean HbA1c values of the patient group $(p=0.975)$. No blood test was performed inthe control group and therefore no comparison was made with patient group. Laboratory findings of the patient group are summarized in Table 2.

\section{Electrocardiographic Findings}

In the patient group there was a statistically significant increase in terms of $\mathrm{HR}, \mathrm{Pd}, \mathrm{QTd}$ and QTcd in the first ECGs, obtained at the time of DKA, when compared to both the second and third (after treatment) ECGs (Table 3). A significant increase in Tp-e and Tp-e/QT was found when the first ECGs were compared to third ECGs ( $p=0.045$ and $p<0.001$, respectively) and there was a significant increase in Tp-e/QT in the first and second ECGs compared to the third ECGs $(p<0.001$ and $p=0.013$, respectively). There was no significant difference in Tp-e/QTc in any of the inter-group comparisons $(p>0.05)$. Significant differences were found in the parameters HR, Pd, QTd, QTcd and Tp-e/ QT between the three ECGs obtained at different times. In terms of Tp-e/QT, a significant difference was found when comparing the third ECGs with the first and second ECGs $(p=0.013)$. The maximum QTc value of nine patients was found to be increased ( $>450 \mathrm{~ms}$ ) in the first ECG. This persisted in two of these patients in the second ECGs but all of them had recovered by the third ECG.

\begin{tabular}{|c|c|c|c|c|}
\hline Blood samples & Mean \pm SD & Minimum & Maximum & Laboratory reference range \\
\hline Leukocyte count $\left(/ \mathrm{mm}^{3}\right)$ & $16857 \pm 11825$ & 3900 & 57300 & $4000-10000$ \\
\hline Hemoglobin (g/dL) & $14.18 \pm 1.40$ & 10.2 & 18.0 & $12.1-17.2$ \\
\hline Platelet count $\left(/ \mathrm{mm}^{3}\right)$ & $331143 \pm 123929$ & 33.000 & 700.000 & $150000-400000$ \\
\hline Blood glucose (mg/dL) & $446.17 \pm 133.83$ & 225 & 947 & $\begin{array}{l}\text { Fasting: } 70-105 / \\
\text { Postprandial: } 80-140\end{array}$ \\
\hline Urea (mg/dL) & $33.94 \pm 21.28$ & 12.5 & 125.6 & $16.6-48.8$ \\
\hline Creatinine (mg/dL) & $0.84 \pm 0.30$ & 0.40 & 1.91 & $0.39-0.87$ \\
\hline Sodium $(\mathrm{mmol} / \mathrm{L})$ & $133.82 \pm 4.61$ & 125 & 147 & $136-145$ \\
\hline Potassium (mmol/L) & $4.44 \pm 0.82$ & 2.6 & 6.4 & $3.5-5.1$ \\
\hline Chlorine (mmol/L) & $99.03 \pm 6.79$ & 82 & 115 & $98-107$ \\
\hline Calcium (mg/dL) & $9.33 \pm 0.80$ & 6.88 & 10.71 & 8.4-10.2 \\
\hline Phosphorus (mg/dL) & $3.97 \pm 1.35$ & 1.71 & 7.82 & $2.9-5.1$ \\
\hline Magnesium (mg/dL) & $1.98 \pm 0.33$ & 1.56 & 3.37 & $1.7-2.2$ \\
\hline Albumin (g/dL) & $4.56 \pm 0.56$ & 3.10 & 5.56 & $3.2-4.5$ \\
\hline $\mathrm{pH}$ & $7.12 \pm 0.12$ & 6.88 & 7.29 & $7.35-7.45$ \\
\hline $\mathrm{pCO}_{2}(\mathrm{mmHg})$ & $22.53 \pm 6.80$ & 10.2 & 41.2 & $35-45$ \\
\hline $\mathrm{HCO}_{3}(\mathrm{mEq} / \mathrm{L})$ & $7.70 \pm 3.88$ & 3 & 15 & $21-27$ \\
\hline Ketone (serum) & $2.08 \pm 0.77$ & 1 & 3 & 0 \\
\hline Total cholesterol (mg/dL) & $167.30 \pm 47.09$ & 70 & 277 & $0-200$ \\
\hline Triglyceride (mg/dL) & $216.27 \pm 183.43$ & 42 & 979 & $0-150$ \\
\hline HDL (mg/dL) & $40.21 \pm 13.55$ & 10 & 66 & $35-70$ \\
\hline $\mathrm{LDL}(\mathrm{mg} / \mathrm{dL})$ & $90.33 \pm 35.19$ & 32 & 163 & $0-100$ \\
\hline $\operatorname{HbA1c}(\%)$ & $12.65 \pm 2.92$ & 5.5 & 18.0 & $4-6$ \\
\hline
\end{tabular}


The parameters HR, Pd, PR, QTd, QTcd, Tp-e and Tp-e/QT all differed significantly between the first ECG performed in the patient group and the values obtained from the control group. There was a statistically significant increase in PR interval when the second and third ECGs were compared to the control ECGs ( $p=0.005$ and $p=0.032$, respectively). Thus, PR interval was found to be significantly increased compared to controls in all patient group ECGs, while Tp-e/ QTC was similar between all the groups. ECG findings of the groups were summarized in Table 3 and illustrated in Figure 1 and Figure 2.

The EF value in the patient group was slightly but significantly greater than in the control group $(p=0.035)$. Nevertheless, the EF values of both groups were within the normal range. Other parameters were similar between the groups. Comparative results of the ECHO examinations of the cases are given in Table 4.

\section{Discussion}

DM is a complex metabolic disorder characterized by chronic hyperglycemia resulting from defects in insulin secretion and/or insulin sensitivity (10). In T1DM, women and men are affected almost equally. Some populations, including Western Europe and the USA, have a slight male dominance and some societies, such as Japan, have a female dominance (1). It has been reported that the incidence of
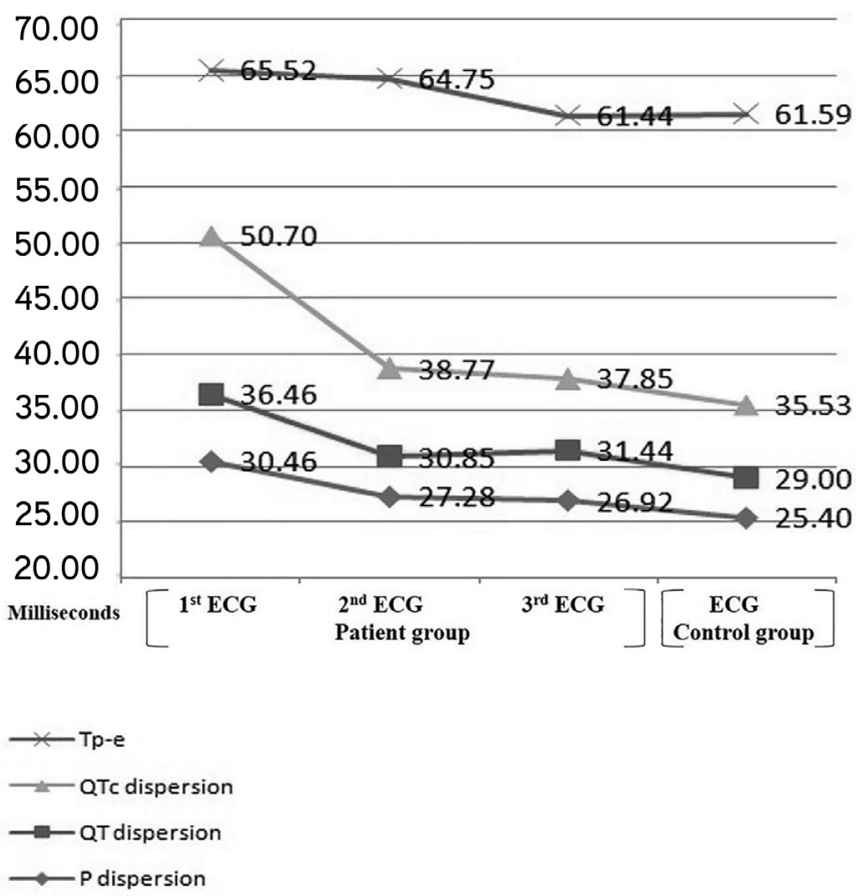

Figure 1. Mean values of P-wave dispersion, QT dispersion, corrected QT dispersion and Tp-e in patient and control groups ECG: electrocardiography
DKA in children does not change with gender (11). However, the incidence of having DKA at first presentation leading to diagnosis of T1DM was found to be higher in boys (female/ male ratio 0.51:1) (12). In our study, male gender was more predominant in newly diagnosed patients, consistent with the literature, while the female to male ratio was determined to be higher in all patients with DKA compared to previous studies. Thus the rate of DKA events in our previously diagnosed patients was greater in girls.

Lipid disturbances, including hypertriglyceridemia and low high density lipoprotein cholesterol, in patients with T1DM have been recognized for some time (13). Dyslipidemia has been associated with poor glycemic control (14). However, studies showing hyperlipidemia in DKA are rarely seen in the literature $(15,16)$. In our patient group, only mild mean triglyceride elevation was seen, although it should be noted that the lipid profiles in our patient group was not taken at the time of DKA. In a multi-center study conducted by Turton et al (17), the HbA1c level in patients with T1DM ranged between 6.8 and $11.1 \%$. In another study in children with T1DM, mean HbA1c level was found to be $7.59 \pm 1.34 \%$ between $0-5$ years of age, $7.61 \pm 1.32 \%$ between $6-12$ years of age, and $8.46 \pm 1.85 \%$ between $13-18$ years of age (18). DKA was more frequent in children with T1DM and poor glycemic control (2). Since all our cases, by definition,were children with DKA and more than $50 \%$ of them were newly diagnosed for T1DM, the mean HbA1c value in our cohort was much higher than previous studies.

In a previous study, the rate of DKA in children with T1DM was found to be inversely proportional to age. The

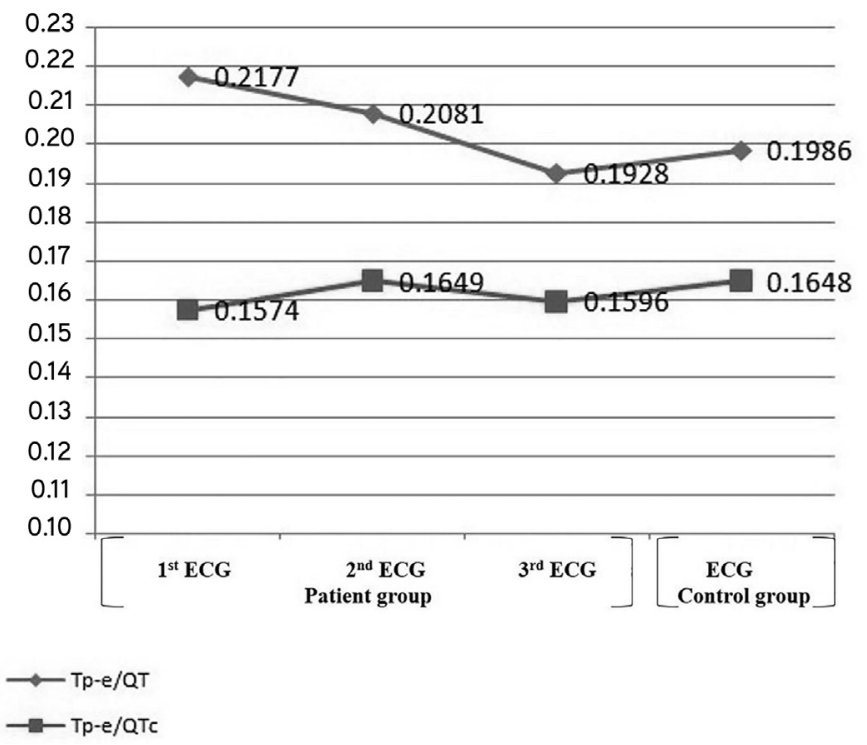

Figure 2. Mean values of Tp-e/QT and Tp-e/QTc ratios in patient and control groups

ECG: electrocardiography 
Table 3. Electrocardiographic findings incases and controls

\begin{tabular}{|c|c|c|c|c|c|c|c|}
\hline & \multicolumn{4}{|l|}{ Mean \pm SD } & \multicolumn{3}{|l|}{$\mathrm{p}$ values } \\
\hline & \multirow{2}{*}{$\begin{array}{l}\text { Patient group } \\
\mathbf{1}^{\text {st }} \text { ECG }\end{array}$} & \multirow{2}{*}{$\begin{array}{l}\text { Patient group } \\
2^{\text {nd }} E C G\end{array}$} & \multirow{2}{*}{$\begin{array}{l}\text { Patient group } \\
3^{\text {rd }} \text { ECG }\end{array}$} & \multirow[t]{2}{*}{ Control group ECG } & $\mathrm{p} 1$ & $\mathrm{p} 2$ & p3 \\
\hline & & & & & $\mathrm{p} 4$ & p5 & p6 \\
\hline $\mathrm{HR}(/ \mathrm{min})$ & $118.12 \pm 23.91$ & $97.52 \pm 25.15$ & $89.48 \pm 18.48$ & $92.20 \pm 27.78$ & $\begin{array}{l}<0.001 \\
<0.001\end{array}$ & $\begin{array}{l}0.067 \\
0.133\end{array}$ & $\begin{array}{l}<\mathbf{0 . 0 0 1} \\
0.992\end{array}$ \\
\hline $\mathrm{P}-\mathrm{min}(\mathrm{ms})$ & $126.20 \pm 22.09$ & $128.74 \pm 20.38$ & $125.13 \pm 17.84$ & $116.09 \pm 18.15$ & $\begin{array}{l}0.455 \\
0.218\end{array}$ & $\begin{array}{l}0.498 \\
\mathbf{0 . 0 4 1}\end{array}$ & $\begin{array}{l}0.006 \\
0.007\end{array}$ \\
\hline $\mathrm{P}-\max (\mathrm{ms})$ & $55.08 \pm 8.81$ & $56.46 \pm 8.82$ & $57.53 \pm 7.88$ & $52.70 \pm 7.24$ & $\begin{array}{l}0.286 \\
\mathbf{0 . 0 0 1}\end{array}$ & $\begin{array}{l}0.535 \\
0.008\end{array}$ & $\begin{array}{l}0.893 \\
0.002\end{array}$ \\
\hline $\mathrm{Pd}(\mathrm{ms})$ & $85.64 \pm 10.53$ & $83.74 \pm 10.38$ & $84.44 \pm 9.69$ & $78.10 \pm 7.58$ & $\begin{array}{l}0.035 \\
0.003\end{array}$ & $\begin{array}{l}0.927 \\
0.398\end{array}$ & $\begin{array}{l}\mathbf{0 . 0 1 7} \\
0.272\end{array}$ \\
\hline PR (ms) & $30.46 \pm 7.56$ & $27.28 \pm 7.16$ & $26.92 \pm 5.89$ & $25.40 \pm 4.40$ & $\begin{array}{l}0.363 \\
0.029\end{array}$ & $\begin{array}{l}0.179 \\
0.005\end{array}$ & $\begin{array}{l}0.854 \\
0.032\end{array}$ \\
\hline QT-min (ms) & $280.31 \pm 28.41$ & $308.72 \pm 38.23$ & $314.39 \pm 29.26$ & $303.10 \pm 36.05$ & $\begin{array}{l}<0.001 \\
<0.001\end{array}$ & $\begin{array}{l}0.127 \\
1.000\end{array}$ & $\begin{array}{l}<\mathbf{0 . 0 0 1} \\
0.370\end{array}$ \\
\hline QT-max (ms) & $316.77 \pm 27.26$ & $339.56 \pm 39.17$ & $345.83 \pm 30.92$ & $332.10 \pm 36.83$ & $\begin{array}{l}<0.001 \\
0.015\end{array}$ & $\begin{array}{l}0.145 \\
0.821\end{array}$ & $\begin{array}{l}<0.001 \\
0.193\end{array}$ \\
\hline QTd (ms) & $36.46 \pm 7.87$ & $30.85 \pm 9.61$ & $31.44 \pm 9.89$ & $29.00 \pm 5.26$ & $\begin{array}{l}0.002 \\
<0.001\end{array}$ & $\begin{array}{l}0.969 \\
1.000\end{array}$ & $\begin{array}{l}0.005 \\
0.613\end{array}$ \\
\hline $\mathrm{QTc}-\min (\mathrm{ms})$ & $387.89 \pm 22.00$ & $384.92 \pm 20.67$ & $379.09 \pm 23.33$ & $367.01 \pm 23.58$ & $\begin{array}{l}0.533 \\
<0.001\end{array}$ & $\begin{array}{l}0.352 \\
\mathbf{0 . 0 0 1}\end{array}$ & $\begin{array}{l}0.127 \\
\mathbf{0 . 0 2 8}\end{array}$ \\
\hline QTc-max (ms) & $438.60 \pm 17.77$ & $423.69 \pm 21.28$ & $416.94 \pm 22.45$ & $402.54 \pm 25.09$ & $\begin{array}{l}0.001 \\
<0.001\end{array}$ & $\begin{array}{l}0.176 \\
<0.001\end{array}$ & $\begin{array}{l}<0.001 \\
0.015\end{array}$ \\
\hline QTcd (ms) & $50.70 \pm 12.01$ & $38.77 \pm 12.38$ & $37.85 \pm 11.38$ & $35.53 \pm 8.15$ & $\begin{array}{l}<0.001 \\
<0.001\end{array}$ & $\begin{array}{l}0.585 \\
0.462\end{array}$ & $\begin{array}{l}<0.001 \\
0.603\end{array}$ \\
\hline Tp-e (ms) & $65.52 \pm 8.48$ & $64.75 \pm 10.05$ & $61.44 \pm 8.04$ & $61.59 \pm 8.29$ & $\begin{array}{l}0.691 \\
\mathbf{0 . 0 4 1}\end{array}$ & $\begin{array}{l}0.054 \\
0.132\end{array}$ & $\begin{array}{l}0.045 \\
0.934\end{array}$ \\
\hline Tp-e/QT & $0.21 \pm 0.03$ & $0.21 \pm 0.04$ & $0.19 \pm 0.03$ & $0.20 \pm 0.02$ & $\begin{array}{l}0.143 \\
0.001\end{array}$ & $\begin{array}{l}\mathbf{0 . 0 1 3} \\
0.195\end{array}$ & $\begin{array}{l}<\mathbf{0 . 0 0 1} \\
0.292\end{array}$ \\
\hline Tp-e/QTc & $0.16 \pm 0.02$ & $0.16 \pm 0.03$ & $0.16 \pm 0.02$ & $0.16 \pm 0.02$ & $\begin{array}{l}0.134 \\
0.120\end{array}$ & $\begin{array}{l}0.090 \\
0.979\end{array}$ & $\begin{array}{l}0.596 \\
0.319\end{array}$ \\
\hline
\end{tabular}

HR: heart rate, P-min: minimum P wave duration, P-max: maximum P wave duration, Pd: P-wave dispersion, QT-min: minimum QT duration, QT-max: maximum QT duration, QTd: QT dispersion, QTc-min: minimum QTc duration, QTc-max: maximum QTc duration, QTcd: QTc dispersion, p1: p value comparing 1 ${ }^{\text {st }}$ and $2^{\text {nd }}$ ECG, p2: p value comparing $2^{\text {nd }}$ and $3^{\text {rd }}$ ECG, $p 3$ : p value comparing $1^{\text {st }}$ and $3^{\text {rd }}$ ECG, $p 4: p$ value comparing $1^{\text {st }}$ case and control ECGs, p5: p value comparing $2^{\text {nd }}$ case and control ECGs, p6: $p$ value comparing $3^{\text {rd }}$ case and control ECGs, SD: standard deviation, ECG: electrocardiography

\begin{tabular}{|c|c|c|c|}
\hline Mean \pm SD & Patient group $(n=39)$ & Control group $(n=40)$ & $\mathrm{p}$ values \\
\hline LA (mm) & $24.38 \pm 4.10$ & $24.47 \pm 4.15$ & 0.949 \\
\hline Ao $(\mathrm{mm})$ & $20.38 \pm 3.59$ & $20.43 \pm 2.98$ & 0.960 \\
\hline LA/Ao & $1.20 \pm 0.10$ & $1.20 \pm 0.13$ & 0.986 \\
\hline LVESD (mm) & $21.95 \pm 3.88$ & $23.63 \pm 4.51$ & 0.081 \\
\hline LVEDD (mm) & $37.42 \pm 6.22$ & $39.46 \pm 6.69$ & 0.159 \\
\hline IVSd (mm) & $6.66 \pm 1.10$ & $7.03 \pm 1.18$ & 0.127 \\
\hline LVPWd (mm) & $6.74 \pm 1.09$ & $6.94 \pm 1.30$ & 0.473 \\
\hline $\mathrm{EF}(\%)$ & $72.79 \pm 3.82$ & $71.00 \pm 3.60$ & 0.035 \\
\hline FS (\%) & $40.72 \pm 4.62$ & $40.03 \pm 3.44$ & 0.113 \\
\hline
\end{tabular}

Ao: aortic root, EF: left ventricular ejection fraction, FS: left ventricular fractional shortening, IVSd: end-diastolic interventricular septal thickness, LA: left atrial diameter, LVEDD: left ventricular end-diastolic dimension, LVESD: left ventricular end-systolic dimension, LVPWd: end-diastolic left ventricular posterior wall thickness, SD: standard deviation

prevalence of DKA was $36 \%$ under 5 years of age, where as it was $16 \%$ in those older than 14 years old (11). The incidence of having DKA at the onset of diagnosis of T1DM varies widely between $14.7 \%$ and $79.8 \%$ in various countries (19). Große et al (19) reported that the rate of DKA at the time of T1DM diagnosis increased in countries closer to the equator or there was a higher sensitivity to diabetic symptoms. The same article reported the rate of 
concurrent DKA and T1DM diagnosis as $65.9 \%$ for Turkey, in accordance with our data.

The use of insulin in diabetic patients has greatly reduced the risk of mortality due to DKA, but cardiovascular dysfunction continues to be an important cause of mortality in the chronic disease process (20). Diabetes is recognized as a strong and independent risk factor for cardiovascular morbidity and mortality, which in turn are frequently associated with rhythm disturbances, such as atrial fibrillation and ventricular arrhythmia (21). Autoimmune mechanisms, which are also important in the etiology of T1DM, may be involved in the pathogenesis of cardiac autoimmunity (22). Lipid disorders have also been shown to contribute to this process by increasing atherosclerotic risk (23). It has been reported that cardiovascular risk was increased tenfold in individuals with T1DM compared to the healthy population (24).

The ECG parameters Pd, QTd, QTcd,Tp-e, Tp-e/QT, and Tp-e/QTc have been shown to berisk markers and are used to predict the risk of cardiac arrhythmias $(4,5)$. Yet, there is limited data on arrhythmia risk markers in children with DKA. In studies performed in adult (25) and pediatric patients with T1DM $(5,26)$, Pd was reported to be significantly increased compared to controls. In a study conducted in adult T2DM patients with DKA, it was observed that Pd was increased significantly before DKA treatment compared to after treatment (27). In another study evaluating children with DKA, it was reported that the mean $\mathrm{P}$ wave duration before DKA treatment was significantly increased compared to after treatment, however $\mathrm{Pd}$ assessment was not performed in that study (28). To the best of our knowledge, there has been no study reporting the relationship between $\mathrm{Pd}$ and DKA in a pediatric population. In our study, Pd in the first, pre-DKA treatment, ECG was found to be significantly higher than both the second and third ECGs, which were obtained after treatment, and the Pd value concurrent with DKA was also greater than in the control group ECGs. Our findings suggest that there may be an increased risk of atrial arrhythmia at the time of DKA in children with T1DM.

QTd and QTcd have been associated with an increased risk of malignant ventricular arrhythmia (29). QTd values above $58 \mathrm{~ms}$ in healthy individuals increase the cardiovascular mortality risk by 3.2 times and if QTd is above $80 \mathrm{~ms}$, it has been reported to increase four times (30). QTd and QTcd were associated with a risk of cardiac arrhythmia in studies conducted in adults $(31,32)$ and children $(4,33)$ with T1DM. In an adult study of T1DM patients with DKA, QTC was found to be prolonged ( $>450 \mathrm{~ms}$ ) in $38(62.3 \%$ ) of 61 patients, regardless of potassium level (34). It was also reported that the QTd and QTcd values obtained during
DKA in children with T1DM were increased compared to the healthy population $(35,36)$. In our study, QTd and QTcd in the first patient group ECG were found to be significantly prolonged compared to both second and third ECGs, as well as the ECGs of the control group. This also suggests that there is an increased risk of ventricular arrhythmia in children with T1DM especially during episodes of DKA.

The results of studies on Tp-e, Tp-e/QT and Tp-e/QTc values in adult T1DM patients are controversial. Inanır et al (32) reported these parameters to be increased in adults with T1DM compared to their control group, whereas in another study, these ECG parameters were found to be similar between T1DM patients and controls (37). In the study of Güney et al (26), conducted in children with T1DM, Tp-e was increased compared to the control group, but Tp-e/QT and Tp-e/QTc ratios were similar with healthy controls. We could not find any data in the literature about Tp-e, Tp-e/QT or Tp-e/QTc in a pediatric population with DKA. In our study, a statistically significant increase was found in pre-treatment ECGs in Tp-e and Tp-e/QT values compared to the control group. However, these parameters were similar between the values obtained at the third ECG and controls. In the study of Güney et al (26), all patients with T1DM were previously diagnosed, whereas our patient group was composed of more than half newly diagnosed T1DM. Additionally, there was no significant difference in regard to Tp-e/QTc in our study. This may be attributed to the fact that QTc values increases much more than $\mathrm{QT}$ as the HR increases. So the rise in Tp-e and of its variations in children diagnosed with T1DM related DKA remains controversial.

\section{Study Limitations}

Due to the limited number of cases, the previously and newly diagnosed T1DM patients could not be differentiated during the evaluation. ECG examinations were not standardized during the episode of DKA, since the focus of this study was mostly ECG markers related to cardiac arrhythmia risk.In addition, 24-hour holter monitoring couldn't get recorded due to technical incompetence.

\section{Conclusion}

In conclusion, the current study was a prospective study conducted in children with T1DM and experiencing an episode of DKA. To the best of our knowledge, this is the first article evaluating $\mathrm{Pd}$, Tp-e, Tp-e/QT and Tp-e/QTc parameters in children with DKA. In this study, cardiac arrhythmia risk markers were increased in children with DKA. While T1DM is already considered a risk factor for cardiac arrhythmias, DKA has been observed to contribute 
to this process. We found that the increase in cardiac arrhythmia risk markers during DKA persisted for a while immediately after the DKA symptoms and/or signs recovered, at the time of the second ECG, but they were similar to the control group 2-3 weeks after the episode of DKA. Thus, we suggest that it is important to consider the possibility of atrial and/or ventricular arrhythmias that may develop during treatment and immediate follow-up period in children with T1DM who have an episode of DKA in order to avoid adverse cardiac events. However, further prospective studies, including larger numbers of patients and longer follow-up periods, are needed to better understand the risks.

\section{Ethics}

Ethics Committee Approval: Ethical approval for the study was obtained from Necmettin Erbakan University Ethical Committee with a decision no. 2018/1321, dated 03.05.2018.

Informed Consent: Informed consent was obtained from all individual participants and/or their legal guardians included in the study.

Peer-review: Externally peer-reviewed.

\section{Authorship Contributions}

Surgical and Medical Practices: Oğuz Eğil, Fatih Şap, Beray Selver Eklioğlu, Mehmet Burhan Oflaz, Mehmet Emre Atabek, Tamer Baysal, Concept: Fatih Şap, Beray Selver Eklioğlu, Mehmet Burhan Oflaz, Design: Fatih Şap, Beray Selver Eklioğlu, Mehmet Burhan Oflaz, Data Collection or Processing: Oğuz Eğil, Fatih Şap, Beray Selver Eklioğlu, Analysis or Interpretation: Mehmet Emre Atabek, Tamer Baysal, Literature Search: Oğuz Eğil, Mehmet Burhan Oflaz, Writing: Oğuz Eğil, Fatih Şap.

Financial Disclosure: This study was funded by Necmettin Erbakan University's Scientific Research Project Coordinator (decision no. 181518017, dated 05.10.2018), which allowed supply of electrocardiography device and its equipments.

\section{References}

1. Weber DR, Jospe N. Diabetes mellitus. In: Kliegman RM, St Geme JW, Blum NJ, Shah SS, Tasker RC, Wilson KM, Behrman RE (eds). Nelson Textbook of Pediatrics. 21 st ed. Philadelphia, Elsevier, 2019;11814-11935.

2. Wolfsdorf JI, Glaser N, Agus M, Fritsch M, Hanas R, Rewers A, Sperling MA, Codner E. ISPAD Clinical Practice Consensus Guidelines 2018: Diabetic ketoacidosis and the hyperglycemic hyperosmolar state. Pediatr Diabetes 2018;19(Suppl 27):155-177.

3. Larsson SC, Wallin A, Håkansson N, Stackelberg O, Bäck M, Wolk A. Type 1 and type 2 diabetes mellitus and incidence of seven cardiovascular diseases. Int J Cardiol 2018;262:66-70. Epub 2018 Mar 24
4. Castro-Torres Y, Carmona-Puerta R, Katholi RE. Ventricular repolarization markers for predicting malignant arrhythmias in clinical practice. World J Clin Cases 2015;3:705-720.

5. Imamoglu EY, Oztunc F, Eroglu AG, Onal H, Guzeltas A. Dispersion of the $\mathrm{P}$ wave as a test for cardiac autonomic function in diabetic children. Cardiol Young 2008;18:581-585. Epub 2008 Oct 2

6. von Oettingen J, Wolfsdorf J, Feldman HA, Rhodes ET. Use of serum bicarbonate to substitute for venous $\mathrm{pH}$ in new-onset diabetes. Pediatrics 2015;136:371-377. Epub 2015 Jul 20

7. Lepeschkin E, Surawicz B. The Measurement of the Q-T Interval of the Electrocardiogram. Circulation 1952;6:378-388.

8. Lopez L, Colan SD, Frommelt PC, Ensing GJ, Kendall K, Younoszai AK, Lai WW, Geva T. Recommendations for quantification methods during the performance of a pediatric echocardiogram: a report from the Pediatric Measurements Writing Group of the American Society of Echocardiography Pediatric and Congenital Heart Disease Council. J Am Soc Echocardiogr 2010;23:465-495.

9. Mukaka MM. A guide to appropriate use of Correlation coefficient in medical research. Malawi Med J 2012;24:69-71.

10. Mayer-Davis EJ, Kahkoska AR, Jefferies C, Dabelea D, Balde N, Gong CX, Aschner P, Craig ME. ISPAD Clinical Practice Consensus Guidelines 2018: Definition, epidemiology, and classification of diabetes in children and adolescents. Pediatr Diabetes 2018;19(Suppl 27):7-19.

11. Wolfsdorf JI, Glaser N, Sperling MA; American Diabetes Association. Diabetic ketoacidosis in infants, children, and adolescents: A consensus statement from the American Diabetes Association. Diabetes Care 2006;29:1150-1159

12. Dabelea D, Rewers A, Stafford JM, Standiford DA, Lawrence JM, Saydah S, Imperatore G, D’Agostino RB Jr, Mayer-Davis EJ, Pihoker C; SEARCH for Diabetes in Youth Study Group. Trends in the prevalence of ketoacidosis at diabetes diagnosis: the SEARCH for diabetes in youth study. Pediatrics 2014;133:938-945. Epub 2014 Mar 31

13. O’Brien T, Nguyen TT, Zimmerman BR. Hyperlipidemia and diabetes mellitus. Mayo Clin Proc 1998;73:969-976.

14. Maahs DM, Dabelea D, D’Agostino RB Jr, Andrews JS, Shah AS, Crimmins N, Mayer-Davis EJ, Marcovina S, Imperatore G, Wadwa RP, Daniels SR, Reynolds K, Hamman RF, Dolan LM; SEARCH for Diabetes in Youth Study. Glucose control predicts 2-year change in lipid profile in youth with type 1 diabetes. J Pediatr 2013;162:101-107. Epub 2012 Jul 11

15. Blackett PR, Holcombe JH, Alaupovic P, Fesmire JD. Plasma Lipids and Apolipoproteins in a 13-year-old Boy With Diabetic Ketoacidosis and Extreme Hyperlipidemia. Am J Med Sci 1986;291:342-346.

16. Gianfrate L, Ferraris L. Acute Pancreatitis, Hyperlipidemia, and Diabetic Ketoacidosis: Who Comes First? Am J Gastroenterol 1998;93:13931394

17. Turton JL, Raab R, Rooney KB. Low-carbohydrate Diets for Type 1 Diabetes Mellitus: A Systematic Review. PLoS One 2018;13:e0194987.

18. Ziegler R, Heidtmann B, Hilgard D, Hofer S, Rosenbauer J, Holl R; DPVWiss-Initiative. Frequency of SMBG correlates with HbA1c and acute complications in children and adolescents with type 1 diabetes. Pediatr Diabetes 2011:11-17.

19. Große J, Hornstein H, Manuwald U, Kugler J, Glauche I, Rothe U. Incidence of Diabetic Ketoacidosis of New-Onset Type 1 Diabetes in Children and Adolescents in Different Countries Correlates with Human Development Index (HDI): An Updated Systematic Review, Meta-Analysis, and Meta-Regression. Horm Metab Res 2018;50:209222. Epub 2018 Mar 9 
20. Dhalla NS, Pierce GN, Innes IR, Beamish RE. Pathogenesis of Cardiac Dysfunction in Diabetes Mellitus. Can J Cardiol 1985;1:263-281.

21. Koektuerk B, Aksoy M, Horlitz M, Bozdag-Turan I, Turan RG. Role of diabetes in heart rhythm disorders. World J Diabetes 2016;7:45-49.

22. Frostegård J. Autoimmunity, oxidized LDL and cardiovascular disease. In: Shoenfeld Y (eds). Autoimmunity Reviews. Solna, Elsevier, 2002;233-237

23. A Feitosa AC, Feitosa-Filho GS, Freitas FR, Wajchenberg BL, Maranhão RC. Lipoprotein metabolism in patients with type 1 diabetes under intensive insulin treatment. Lipids Health Dis 2013;12:15.

24. de Ferranti SD, de Boer IH, Fonseca V, Fox CS, Golden SH, Lavie CJ, Magge SN, Marx N, McGuire DK, Orchard TJ, Zinman B, Eckel RH. Type 1 diabetes mellitus and cardiovascular disease: a scientific statement from the American Heart Association and American Diabetes Association. Diabetes Care 2014;130:1110-1130. Epub 2014 Aug 11

25. Yazici M, Ozdemir K, Altunkeser BB, Kayrak M, Duzenli MA, Vatankulu MA, Soylu A, Ulgen MS. The effect of diabetes mellitus on the P-wave dispersion. Circ J 2007;71:880-883.

26. Güney AY, Şap F, Eklioğlu BS, Oflaz MB, Atabek ME, Baysal T. Investigation of the effect of epicardial adipose tissue thickness on cardiac conduction system in children with type 1 diabetes mellitus. J Pediatr Endocrinol Metab 2020;33:713-720.

27. Fidan C, Bünyamin Yavuz B, Şen Ö, Ertuğrul DT, Yaşar Nazlıgül Y. Increased $\mathrm{P}$ Wave Dispersion In Patients With Diabetic Ketoacidosis. TJFM\&PC 2016;10:63-68.

28. Aygün D, Aygün F, Nişli K, Baş F, Çıtak A. Electrocardiographic changes in children with diabetic ketoacidosis and ketosis. Turk Pediatri Ars 2017;52:194-201.

29. Psallas M, Tentolouris N, Cokkinos A, Papadogiannis D, Cokkinos DV, Katsilambros N. QT dispersion: comparison between diabetic and non-diabetic individuals and correlation with cardiac autonomic neuropathy. Hellenic J Cardiol 2006;47:255-262.

30. Elming $\mathrm{H}$, Holm E, Jun L, Torp-Pedersen C, Køber L, Kircshoff M, Malik M, Camm J. The prognostic value of the QT interval and QT interval dispersion in all-cause and cardiac mortality and morbidity in a population of Danish citizens. Eur Heart J 1998;19:1391-1400.

31. Veglio M, Giunti S, Stevens LK, Fuller JH, Perin PC; EURODIAB IDDM Complications Study Group. Prevalence of $\mathrm{Q}-\mathrm{T}$ interval dispersion in type 1 diabetes and its relation with cardiac ischemia : the EURODIAB IDDM Complications Study Group. Diabetes Care 2002;25:702-707.

32. Inanır M, Gunes Y, Sincer I, Erdal E. Evaluation of Electrocardiographic Ventricular Depolarization and Repolarization Variables in Type 1 Diabetes Mellitus. Arq Bras Cardiol 2020;114:275-280.

33. Suys BE, Huybrechts SJ, De Wolf D, Op De Beeck L, Matthys D, Van Overmeire B, Du Caju MV, Rooman RP. QTc interval prolongation and QTC dispersion in children and adolescents with type 1 diabetes. J Pediatr 2002;141:59-63.

34. Talebi S, Ghobadi F, Cacacho A, Olatunde O, DeRobertis A, Pekler G, Visco F, Mushiyev S, Hassen GW. Looking at diabetic ketoacidosis through electrocardiogram window. Am J Emerg Med 2016;34:263265. Epub 2015 Oct 28

35. Kuppermann N, Park J, Glatter K, Marcin JP, Glaser NS. Prolonged QT interval corrected for heart rate during diabetic ketoacidosis in children. Arch Pediatr Adolesc Med 2008;162:544-549.

36. Youssef OI, Farid SM. QTC and QTd in Children with Type 1 Diabetes Mellitus during Diabetic Ketoacidosis. ISRN Pediatr 2012;2012:619107. Epub 2012 Nov 6

37. Olmez S, Akkoyun M, Şahin M, Namli AR, Akgüngör M, Dirnak I, Göksugur Y, Gül K, Acar G. Evaluation of Tp-e Interval and Tp-e/QT Ratio in Patients with Type 1 Diabetes Mellitus. JACC 2013;62(Suppl 2):147. 